\title{
Intracellular Membrane
}

National Cancer Institute

\section{Source}

National Cancer Institute. Intracellular Membrane. NCI Thesaurus. Code C32876.

A thin pliable sheet separating organelles from the protoplasm. 